\title{
Media Literacy Effect. The Context of War Media Trauma
}

Lyubov Naydonova

Institute for Social and Political Psychology of National Academy of Educational Sciences, Kyiv, Ukraine

Introduction. On the base of analysis of media covering of terrorist bombing and its effect on health (Pfefferbaum, 1999) we proposed war media trauma taxonomy for teenagers. We single out three type of media trauma on the base of composition of real trauma, interpersonal transition, and media exposition:

a) real traumatic event, interpersonal transition of trauma and media exposition,

b) interpersonal transition of trauma and media exposition,

c) only media exposition.

Example of media trauma, type A: media war content impact on the children, which mother has killed by bomb earlier, or teenager, who has lived their destroyed home. Example of media trauma, type B: media war content impact on teenager, which father is combatant right now or some relatives are the participant of war tragedy. Example of media trauma C: media war content impact on children, who only watch TV about antiterrorist operation on the East Ukraine and talk about it by social media.

Purpose. The purpose of the study is to reveal the relationship between war news watching and psychological well-being as an indicator of mediatrauma type $\mathrm{C}$, to determine the role of media literacy in the prevention of negative media effects.

Methodology. Ukrainian teenagers (13-17 years old, from experimental schools with media educational curriculum, $\mathrm{N}=1144$ ) were answering set of question during 2015 year, when war events were on the Donbass (East Ukraine) and actively enlightened by media. Media coverage of military news message includes daily the number of attacks, killed and injured combatants, farewell to the dead in the central area of the country's Independence Square, the life of soldiers in the line of confrontation, pre-war life, affected civilians, the treatment of combatants, veterans' achievements.

Results. As a result, 57\% of teenagers watch TV news about war every day or almost every day, $44 \%$ talk about it always or often. Very small significant relationships were found between watching war news and psychological well-being $(\rho=.195 * *)$, and between news discussion and psychological well-being $(\rho=.223 * *)$ for teenagers with low levels of media literacy. Teenagers, who have low levels of media literacy and refuse to watch the news and discuss them, have lower psychological well-being. At a high level, media literacy significant relationships were not found. Media trauma (type C), which symptoms are demonstrated by TV spectators in cases of media coverage of terrorist acts or techno disaster, is not found in adolescents who view extended coverage of war.

Conclusions. We proposed for media trauma effect measurement not only PTSD symptoms approach but also the level of psychological well-being (Ryff, 1995, Shyshko, 2015). Media literacy level could be evaluated by object knowledge express test (Naydonova, 2016), which is appropriated for course "Media culture" for pupils of 10 classes of secondary schools. Watching of military news and their discussion becomes the home practices as form of stress coping. It was found the moderated effect of media literacy. The next stage of research involves the study of the role of media in covering the military actions for different types of mediatrauma.

Keywords: media literacy, news, war trauma, teenager, well-being 


\section{References.}

Naydonova, L.A. (2016) Diagnosis of Knowledge Component of Media Information Literacy. Kyiv.

Pfefferbaum, B, Moore, V L, McDonald, N B, Maynard, B T, Gurwitch, R H, Nixon, S J. (1999) The role of exposure in posttraumatic stress in youths following the 1995 bombing. The Journal of the Oklahoma State Medical Association, 92 (4), 164-167.

Ryff, C. D., Keyes, C.L.M. (1995) The Structure of Psychological Well-Being Revisited. Journal of Personality and Social Psychology, 69 (4), 719-727.

Shyshko N.S. (2015) Psychological well-being in the in the representations of modern high school students. Kyiv. 